\title{
Neoadjuvant Therapy for Non-melanoma Skin Cancer: Updated Therapeutic Approaches for Basal, Squamous, and Merkel Cell Carcinoma
}

Enrico Zelin, $M D^{1, *}$ 。 Iris Zalaudek, $M D^{1}$ Marina Agozzino, $M D^{1}$ Caterina Dianzani, $M D^{2}$ Arianna Dri, $M D^{1}$ Nicola Di Meo, $M D^{1}$

Roberta Giuffrida, $M D^{3}$ Giovanni Francesco Marangi, $M D^{2}$ Nicoleta Neagu, MD ${ }^{4}$ Paolo Persichetti, $M D^{2}$ Ludovica Toffoli, $M D^{1}$ Claudio Conforti, $M D^{1}$

\footnotetext{
atates

${ }^{*}, 1$ Dermatology Clinic, Maggiore Hospital, University of Trieste, Piazza dell'0spitale 1,34129, Trieste, Italy Email: enrico.zelin@gmail.com

${ }^{2}$ Plastic and Reconstructive Surgery Department, Campus Biomedico University, Rome, Italy

${ }^{3}$ Department of Clinical and Experimental Medicine, Dermatology Section, University of Messina, Messina, Italy

${ }^{4}$ Dermatology Clinic, Mures Country Hospital, Tirgu Mures, Romania
}

(C) The Author(s) 2021

This article is part of the Topical Collection on Skin Cancer 
Keywords Non-melanoma skin cancer - Basal cell carcinoma - Squamous cell carcinoma - Merkel cell carcinoma • Neoadjuvant treatment $\cdot$ Targeted therapy $\cdot$ Immunotherapy $\cdot$ Vismodegib $\cdot$ Sonidegib

\section{Opinion statement}

Recently introduced systemic therapies for locally advanced and metastatic nonmelanoma skin cancers (NMSCs) are paving the way for neoadjuvant approach. Although none of the therapeutic options has currently gained indication in this setting, neoadjuvant approach for NMSCs is an open field and we are likely to see huge developments in the near future. Targeted therapy with sonic hedgehog pathway inhibitors is very effective in locally advanced or multiple basal cell carcinomas while immunotherapy with immune checkpoint inhibitors appears to be promising for advanced cutaneous squamous cell carcinoma and Merkel cell carcinoma. To date, targeted therapy and immunotherapy represent the frontiers in NMSC therapeutic management and, according to recent studies, good results can be achieved.

\section{Introduction}

\section{Non-melanoma skin cancers: background}

Non-melanoma skin cancers (NMSCs) are the most common malignancies, accounting for up to $30 \%$ of all human tumors [1,2]. Basal cell carcinomas (BCCs) and cutaneous squamous cell carcinomas (CSCCs) are keratinocyte cancers and represent the most common NMSCs, while rarer tumors included in this category are Merkel cell carcinoma (MCC), cutaneous sarcomas, appendageal tumors, and cutaneous lymphomas [2]. The incidence of keratinocyte cancers is steadily growing, probably due to different factors (ageing population, increasing ultraviolet radiation exposure, raising number of immunosuppressed individuals, and possibly greater awareness of the disease and earlier diagnosis) $[1,3]$. BCC to CSCC incidence ratio varies between $4: 1$ and 1:1, according to different sources [1-3]. Although the primary aim is to perform an early diagnosis through minimally invasive procedures such as dermoscopy [46], advanced tumors are not uncommon and require a more challenging treatment.

\section{Conventional treatment options and definition of neoadjuvant approach}

Surgical excision is regarded as the therapeutic gold standard for most NMSCs and together with radiotherapy is considered a potentially curative treatment [7]. Radiotherapy is an effective non-surgical option and it is used in the definitive, adjuvant, and palliative settings for these malignancies $[7,8 \bullet]$. It is well-tolerated and may offer a better cosmetic and functional outcome in comparison with surgery $[7,8 \bullet]$. NMSCs are radioresponsive and local control rates are excellent, irrespective of the radiotherapy dose or dose per fraction (local control rate at 5 years of $92 \%$ for cSCC and 96\% for BCC, according to a large study involving 597 patients with 1021 lesions) [9].

In some cases, surgery or radiotherapy cannot be adopted as first step; therefore, a neoadjuvant treatment is indicated. By definition, a neoadjuvant approach aims to reduce the size of the tumor, in order to make it eligible for other potentially curative techniques. The most typical circumstance requiring a neoadjuvant treatment regards advanced tumors, when there may be a significant risk of functional and cosmetic deficit from immediate surgery because of size, number, or location of the cancers [10,11]. In evaluating tumor response to treatment, RECIST (Response Evaluation Criteria In Solid Tumors) criteria are often used, defining complete response (CR), partial response $(\mathrm{PR})$, stable disease $(\mathrm{SD})$, and progressive disease (PD) $[12,13]$.

Herein, we report the most commonly pharmacologic treatments and interventional procedures in advanced NMSC. Currently, none of them has gained indication as neoadjuvant therapy, and evidence on their efficacy in this setting is limited and based on case reports, case series, and often non-randomized small studies. 
Notably, there are no reports of radiotherapy used as neoadjuvant option before surgery in NMSCs, because irradiated tissues are deemed to present poor wound healing [3].

\section{Pharmacologic treatments: targeted therapy}

Targeted therapy interferes with cancer cell growth by blocking specific target molecules needed for carcinogenesis and tumor development. It is much more specific than traditional chemotherapy, which simply affects all rapidly dividing cells. However, targeted therapy is clearly not simple to develop, since these target molecules have to be precisely identified; subsequently, a specific drug that blocks them has to be engineered and the clinical benefit has to be ultimately demonstrated. Vismodegib and sonidegib are sonic hedgehog path-

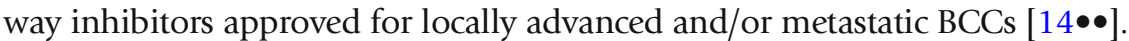
There are no targeted therapies currently approved for advanced cSCC but epidermal growth factor inhibitors have been used so far in some cases [15-21].

\section{Sonic hedgehog pathway inhibitors}

The sonic hedgehog pathway is involved in cell differentiation and proliferation

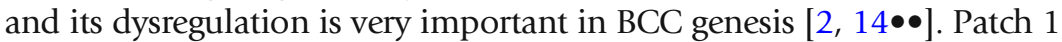
(encoded by PTCH1 gene) is a transmembrane protein that acts as tumor suppressor by inhibiting smoothened (SMO), another transmembrane protein. Physiologic ligands (e.g., sonic hedgehog itself) binding to PTCH1 or loss-offunction PTCH1 mutations (frequently found in both sporadic BCCs and Gorlin-Goltz syndrome-associated BCCs) relieve this inhibition of SMO. This ultimately leads to nuclear translocation of GLI transcription factors and activation of target genes, causing cell proliferation and tumor growth [2]. Vismodegib and sonidegib act by antagonizing SMO and are both currently licensed

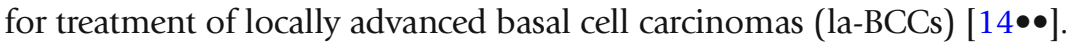
Vismodegib is also approved for metastatic basal cell carcinomas (m-BCCs) $[14 \bullet \bullet]$.

\section{Vismodegib}

Efficacy and safety of vismodegib were firstly assessed in 104 patients suffering from la-BCC $(n=71)$ and m-BCC $(n=33)$ during a follow-up of 39 months in the phase II non-randomized clinical trial ERIVANCE $[22,23]$. Response rate (RR, percentage of complete or partial responses) by investigator review was $60.3 \%$ for la-BCC and $48.5 \%$ for m-BCC, with a median response duration of 26.2 and 14.8 months, respectively [24]. Of note, independent review facility-assessed RR was $43 \%$ in laBCC and 30\% in mBCC [24]. Similar results were reported by the STEVIE trial (based on 1215 patients, 1119 with la-BCC and 96 with m-BCC): investigator-assessed RR was $68.5 \%$ for la-BCC and $36.9 \%$ for $\mathrm{m}$-BCC $[25,26]$.

Vismodegib was also used in combination with radiotherapy in la-BCC with good control of disease, according to a case series and a study involving 24 patients (NCT01835626) [27].

In consideration of its efficacy in tumor burden reduction, vismodegib could be very promising as neoadjuvant treatment in real-life setting, above all in la- 
BCCs, although strong data and evidence are lacking. In 15 patients with la-BCC treated with neoadjuvant vismodegib and subsequent surgical excision, after a follow-up of almost 2 years, only one recurrence was reported [28]. Moreover, there are other ongoing studies investigating the potential of this drug in neoadjuvant setting (NCT03035188, NCT02667574).

Standard dosage

$150 \mathrm{mg} /$ day, oral administration

Contraindications

Hypersensitivity to active principle or bulking agents, pregnancy and lactation, inadequate pregnancy prevention.

When administered together with drugs that increase gastric $\mathrm{pH}$, vismodegib absorption can be reduced. The concomitant use of CYP3A4 inductors (such as rifampicin, carbamazepine, phenytoin, and St. John's herb or Hypericum perforatum) may reduce exposition to vismodegib, while contemporary administration of CYP3A4 inhibitors (e.g., azoles) or Pglycoprotein inhibitors (e.g., clarithromycin, erythromycin, azithromycin) may increase it, but these latter interactions are not clinically significant. Vismodegib may decrease the efficacy of steroid contraceptives and increase the exposition to drugs transported by breast cancer resistance protein (BCRP) (e.g., rosuvastatin, topotecan, sulfasalazine) and to OATP1B1 substrates (e.g., statins, ezetimibe, valsartan, and some antidiabetic drugs) $[29,30]$.

Main adverse effects

Muscular spasms (66\%), alopecia (62\%), dysgeusia (55\%), weight loss (41\%), decreased appetite (25\%), asthenia (24\%), nausea (17.9\%), ageusia (17.5\%), fatigue (16.5\%), diarrhea (16.2\%), arthralgia (10.2\%) [26]. Other adverse effects (reported in $<10 \%$ of patients) are headache, anemia, abdominal pain, cough, pruritus, skin rash, increased levels of liver enzymes, creatine phosphokinase and creatinine, and increased risk of cSCC [26].

Special points

Among sonic hedgehog pathway inhibitors, vismodegib is the only one approved for m-BCC.

The cost is high, considering that this therapy should be maintained as long as possible. 


\section{Sonidegib}

Long-term efficacy and safety of sonidegib were assessed during the randomized phase II trial BOLT, recruiting 230 patients with la-BCC $(n=194)$ or m-BCC $(n=36)$ divided in two arms according to a 2:1 ratio (the first arm receiving $800 \mathrm{mg} /$ day of sonidegib and the second 200 $\mathrm{mg} /$ day, respectively) [31]. The dose of $200 \mathrm{mg} /$ day was the only one to obtain approval, because it was effective and better tolerated [31]. After a median follow-up of 30 months, investigator-assessed RR was $71.2 \%$ for la-BCC and $23.1 \%$ for m-BCC, with median response duration of 15.7 and 18.1 months, and 2-year survival rates of 93.2 and $69.3 \%$, respectively [31]. RR assessed per central review was $56.1 \%$ for la-BCC and $7.7 \%$ for m-BCC [31]. Notably, in BOLT trial, tumor response for la-BCC was evaluated using BCC-modified Response Evaluation Criteria In Solid Tumors (mRECIST), which are more stringent than those used in ERVANCE [31].

There is an ongoing study evaluating sonidegib in neoadjuvant setting for laBCC, followed by surgery or imiquimod (NCT03534947).

Standard dosage

$200 \mathrm{mg} /$ day or $200 \mathrm{mg}$ every other day, oral administration.

\section{Contraindications}

Hypersensitivity to active principle or bulking agents, pregnancy and lactation, inadequate pregnancy prevention.

When administered together with drugs that increase gastric $\mathrm{pH}$, sonidegib absorption may be reduced. Since sonidegib is primarily metabolized by CYP3A4, its inhibitors (e.g., ritonavir, saquinavir, telithromycin, ketoconazole, itraconazole, voriconazole, posaconazole, nefazodone) or inductors (e. g. rifampicin, rifabutin carbamazepine, phenytoin, phenobarbital, and St. John's herb or Hypericum perforatum) can increase or reduce sonidegib concentration, respectively. Moreover, sonidegib is an in vitro inhibitor of CYP2B6, CYP2C9, and BCRP [32].

Muscular spasms (54\%), alopecia (49\%), dysgeusia (44\%), nausea (39\%), diarrhea (32\%), weight loss (30\%), increased levels of creatine phosphokinase $(30 \%)$, fatigue $(30 \%)$, decreased appetite (23\%), myalgia $(19 \%)$, and vomiting $(11 \%)$. Other registered adverse effects were abdominal pain, anemia, headache, pruritus, increased levels of liver enzymes, lipase, amylase and creatinine, increased risk of CSCC [31]. However, the possibility to use the dosage of $200 \mathrm{mg}$ every other day improves patient compliance, reducing the side effects [33]. 
The cost is high, considering that this therapy should be maintained as long as possible.

\section{Epidermal growth factor receptor inhibitors}

The epidermal growth factor receptor (EGFR) signaling pathway plays an important role in keratinocyte proliferation and survival and seems to be involved in cSCC carcinogenesis [34••]. EGFR inhibitors include monoclonal antibodies that bind to the extracellular domain of EGFR (e.g., cetuximab, panitumumab) but also tyrosine kinase inhibitors (TKIs), small molecules that block the activity of the EGFR tyrosine kinase domain, therefore inactivating intracellular signaling (e.g., erlotinib, gefitinib, lapatinib, dacomitinib). It is essential to underline that none of these drugs is approved for cSCC but they have been sometimes used off-label. Mutations of EGFR or molecules involved in the downstream signaling pathway (such as RAS and BRAF) can lead to resistance to EGFR inhibitors, but this occurrence is very uncommon for CSCC $[21,34 \bullet \bullet]$.

\section{EGFR monoclonal antibody inhibitors}

Cetuximab (human-murine chimeric monoclonal IgG1 antibody) is approved in colorectal cancer and head and neck SCC but has been used alone or in combination with either radiotherapy or platinum-based chemotherapy for locally advanced cSCC (la-cSCC) and metastatic cSCC (m-CSCC) $[21,35,36]$. Panitumumab (fully humanized monoclonal IgG2 antibody) is approved for colorectal cancer and has also been used in cSCC [16].

\section{Cetuximab}

In a phase II open-label prospective trial involving 36 patients, cetuximab was used as first-line treatment for unresectable cSCC [15]. The best overall RR was $28 \%$, disease control rate (DCR, percentage of patients who achieved complete response, partial response, or stable disease) at 6 weeks was $69 \%$, but the median progression-free survival (PFS) was only 4.1 months (95\% CI, 1.7 to 5 months) [15]. Similar data were reported in a retrospective case series involving 31 patients with advanced cSCC, with RR of $48.5 \%$, DCR at 6 weeks of $67.8 \%$, and median PFS of 9 months (range, 0-36 months) [21].

Cetuximab combination with radiotherapy or platinum-based chemotherapy allows to reach a greater DCR but response remains short-lived [35, 37, 38]. As a matter of fact, in a phase II open-label prospective trial involving 20 patients with cSCC deemed as inoperable, after 2 months of treatment, RR and PFS were $80 \%$ and 1.6 months for cetuximab plus radiotherapy, $37.5 \%$ and 2.8 months for cetuximab plus carboplatin, 33\% and 1.3 months for cetuximab monotherapy, respectively [37]. In a retrospective study including 12 patients with la-SCC treated with both cetuximab and radiotherapy, RR was $64 \%$ and median PFS was 6.4 months [38]. In another series of eight patients with lacSCC treated with cetuximab and radiotherapy, more durable disease control was reported, with an estimated probability of PFS at 24 months of $83.3 \%$ [35].

Neoadjuvant approach could overcome the problem of short-lasting responses. In neoadjuvant setting, cetuximab was used in monotherapy or 
combined with cisplatin or carboplatin and 5-FU in a group of 34 patients suffering from unresectable cSCC. These protocols showed good response and are very promising, since $92 \%$ of the cetuximab plus chemotherapy group and $55 \%$ of the monotherapy group became eligible for surgery after 9 weeks [36]. An ongoing study is investigating cetuximab as a potential neoadjuvant treatment in la-SCC (NCT02324608).

Standard dosage

Initial dose of $400 \mathrm{mg} / \mathrm{m}^{2}$, followed by subsequent weekly doses of 250 $\mathrm{mg} / \mathrm{m}^{2}$, intravenous administration.

Contraindications

Severe hypersensitivity to cetuximab; thorough risk/benefit assessment is necessary in case of pregnancy, lactation or inadequate pregnancy prevention.

Main drug interactions

If associated to platinum-based chemotherapy, cetuximab increases the frequency of severe leucopenia, neutropenia, and infectious complications. When administered together with fluoropyrimidines, cetuximab increases the risk of cardiac ischemia and palmar-plantar erythrodysesthesia. Association with capecitabine and oxaliplatin increases the frequency of severe diarrhea [39].

Main side effects

Common adverse reactions include skin rashes ( $>80 \%$ of treated patients) such as acneiform rash, pruritus, dry skin, hypertrichosis and nail alterations, S. aureus skin infections, hypomagnesemia $(>10 \%)$, mild to moderate infusion reactions $(>10 \%)$ or severe infusion reactions $(<1 \%)$, headache, conjunctivitis, diarrhea, nausea, vomiting, anorexia, mucositis, increase in liver enzymes levels, fatigue, and hypocalcemia. More severe but quite rare adverse effects are deep venous thrombosis, pulmonary embolism, pulmonary interstitial disease, and Stevens-Johnson syndrome [37, 39, 40].

Cost/cost-effectiveness

The cost is elevated.

\section{Panitumumab}

In an open-label phase II trial involving 16 patients with la-cSCC, panitumumab was characterized by a best RR of 31\%, DCR at 6 weeks of $69 \%$, and median PFS of 8 months, showing comparable efficacy to cetuximab [16]. Another recent retrospective study involved 25 individuals with unresectable CSCC, treated with panitumumab monotherapy or with a combination of this drug plus radiotherapy: the best RR, DCR at 6 weeks, and median PFS of the whole group were $52 \%, 84 \%$, and 6.9 months, respectively [41]. Notably, all 
patients with complete response and more than $50 \%$ of patients with partial response had received concurrent radiotherapy [41].

Standard dosage

$6 \mathrm{mg} / \mathrm{kg}$ every 2 weeks, intravenous administration.

Hypersensitivity to active principle or bulking agents and severe adverse reactions to panitumumab, pulmonary fibrosis, or interstitial pneumonia. Thorough risk/benefit assessment is necessary in case of pregnancy, lactation, or inadequate pregnancy prevention.

Main drug interactions

Avoid association with 5-fluorouracil, leucovorin, and irinotecan (increased incidence of severe diarrhea); avoid association with bevacizumab and chemotherapy (increased incidence of toxicity and mortality) [39].

Cutaneous rashes represent the most common drug-related toxicity, arising in $94 \%$ of treated patients (severe reactions: $23 \%$; lifethreatening reactions: $<1 \%$ ), sometimes with relevant infectious complications such as cellulitis, necrotizing fasciitis, and sepsis. Other adverse effects include nail changes, dyspnea, cough, development or worsening of preexistent interstitial lung disease, hypomagnesemia and hypocalcemia, hypokalemia, nausea, diarrhea, decreased appetite, acute renal failure (as consequence of severe diarrhea and dehydration), conjunctivitis, keratitis, abdominal and dorsal pain, fatigue, and insomnia $[16,39,41]$.

The cost is high.

\section{EGFR tyrosine kinase inhibitors}

Gefitinib, erlotinib, lapatinib, and dacomitinib are EGFR tyrosine kinase inhibitors used in non-small-cell lung cancer and other malignancies such as pancreatic and breast cancer. Although not approved for NMSC, their use has been reported for cSCC not eligible for surgery or radiotherapy [17-20].

In non-randomized phase II studies involving patients with la-cSCC, gefitinib (dose: $250 \mathrm{mg}$ orally daily) was characterized by overall RR of $16 \%$, DCR at 8 weeks of $51 \%$, and a 3.8 months PFS [18], while 
erlotinib (dose: $150 \mathrm{mg}$ orally daily) showed an overall RR of $10 \%$, DCR of $72 \%$ at 6 weeks, and a median PFS of 4.7 months [17].

Gefitinib study involved 37 evaluable patients, while erlotinib study included 29 individuals; in both cases, only partial responses were observed (no complete responses were registered) [17, 18].

In an open-label prospective study, lapatinib (1500 mg/day for 56 days) used in neoadjuvant setting reduced CSCC size in two of eight patients, together with a significant decrease of concomitant actinic keratoses [19]. In another open-label, multicentric, uncontrolled phase II trial involving patients with unresectable or metastatic cSCC, dacomitinib was administered. Considering the 42 evaluable patients, overall RR was $28 \%$ ( $2 \%$ complete response, represented by only one patient; $26 \%$ partial response), DCR was $86 \%$, and median PFS was 6 months [20].

Standard dosage

Oral administration, see text above for single drugs

Hypersensitivity to active principle or bulking agents, history of solid organ transplant, pregnancy, and lactation. Patients with impaired hepatic function and patients with a slow metabolizer CYP2D6 genotype should be strictly monitored for adverse effects.

CYP3A4 inhibitors (i.e., ritonavir, saquinavir, telithromycin, ketoconazole, itraconazole, voriconazole, posaconazole, nefazodone) increase EGFR tyrosine kinase inhibitor concentration and CYP3A4 inductors (i.e., rifampicin, rifabutin carbamazepine, phenytoin, phenobarbital, and St. John's herb or Hypericum perforatum) reduce it. In patients using warfarin, international normalized ratio (INR) should be monitored, because there is an increased risk of its elevation and hemorrhagic events. Gastric pH elevation (such as in proton pump inhibitors use) can reduce drug absorption [42, 43].

Common adverse effects for this drug class are acneiform skin rashes, pruritus, nail changes, fatigue, nausea, vomiting, diarrhea, anorexia, conjunctivitis, hemorrhage, and epistaxis, increase of liver enzymes, and creatinine levels. Interstitial pulmonary disease is rarer but can be severe. Lapatinib has also been associated with left ventricular ejection fraction reduction $[17-20,42]$. 
The cost is elevated.

\section{Pharmacologic treatments: immunotherapy}

Immunotherapy has become a cornerstone for advanced and metastatic cutaneous tumor management and is currently indicated for melanoma, cSCC, and MCC $[44 \bullet \bullet]$. This treatment acts by inhibiting immune checkpoints, such as cytotoxic T-lymphocyte-associated protein 4 (CTLA-4), programmed cell death receptor-1 (PD-1), and programmed cell death ligand-1 (PD-L1), eventually improving the activity of the immune system against the tumoral cells and reducing regulatory $\mathrm{T}$ cell-mediated immunosuppression $[44 \bullet \bullet]$. This mechanism is very convenient if the targeted tumor has an important mutational burden leading to antigenicity, such as melanoma and NMSC [45].

\section{Anti-programmed cell death receptor-1 immune checkpoint inhibitor}

\section{Cemiplimab}

Cutaneous squamous cell carcinoma

Cemiplimab (a human monoclonal anti-PD-1 antibody) is indicated for $\mathrm{m}$-cSCC and la-SCC in patients who are not eligible for curative surgery or radiotherapy. The pivotal trial that led to drug approval was a phase I/II study (EMPOWER-CSCC-1) including a phase I cohort with la-CSCC and m-cSCC (26 patients) and phase II cohort with m-cSCC (59 patients) [46]. For the phase I cohort, RR was 50\% (95\% CI, 30 to 70) and DCR was 65\% (95\% CI, 44 to 83). The duration of response exceeded 6 months in more than half of responders [46]. For the phase II cohort, RR was $47 \%(95 \% \mathrm{CI}$, 34 to 61$)$ and DCR was $61 \%$ (95\% CI, 47 to 74$)$. The estimated probability of PFS at 12 months was 53\% (95\% CI, 37 to 66) and the estimated probability of overall survival at 12 months was $81 \%$ (95\% CI, 68 to 89 ) [46].

These good results underline that cemiplimab could be also useful in neoadjuvant setting for cSCC: currently, several ongoing trials are investigating this hypothesis (NCT04428671, NCT03565783). Interestingly, one of them adopts intralesional cemiplimab administration (NCT03889912). 
resistant to therapy with sonic hedgehog pathway inhibitors

(NCT03132636).

Standard dosage

350 mg every 3 weeks, intravenous administration.

Hypersensitivity to active principle or bulking agents, pregnancy, and lactation. Moreover, exclusion criteria from the studies were autoimmune disease, concurrent cancer, history of solid organ transplant, prior treatment with anti-PD-1/PD-L1 blocking antibodies or other immune checkpoint inhibitor therapy, infection with HIV, hepatitis B or hepatitis C [46].

Main drug interactions

Avoid systemic steroids or immunosuppressants before cemiplimab administration (potential reduction of cemiplimab efficacy).

The most common adverse reactions are fatigue (29\%), skin rash (25\%), diarrhea (22\%), nausea (19\%), musculoskeletal pain (17\%), pruritus (15\%), constipation (12\%), decreased appetite (10\%), liver enzymes, and creatinine serum level elevation, lymphopenia, and anemia. Infusion reactions are generally not severe, whereas immune-related adverse effects can be irreversible, serious, and rarely fatal. Among them, immune-related pneumonitis $(2.4 \%)$, hepatitis $(2.1 \%)$, colitis $(0.9 \%)$, nephritis with renal dysfunction (0.6\%), and endocrinopathies such as thyroiditis,

hypophysitis, adrenal insufficiency, and diabetes mellitus type 1 [46, 48].

Special points

Cemiplimab is the only drug approved for systemic treatment in cSCC

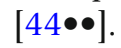

The cost is elevated.

\section{Pembrolizumab and nivolumab}

Pembrolizumab and nivolumab are human monoclonal anti-PD-1 antibodies approved for advanced melanoma and other malignancies including metastatic non-small cell lung cancer, Hodgkin lymphoma, urothelial cancer, renal cancer, head and neck SCC, and Merkel cell carcinoma [49]. 
Pembrolizumab and nivolumab use for unresectable or metastatic cSCC was initially described in case series [49-54]. Good results were reported in an open-label, single-arm, phase II study (KEYNOTE-629) involving 105 patients with recurrent or metastatic cSCC treated with pembrolizumab: RR was $34.3 \%$ ( $95 \%$ CI, $25.3 \%$ to $44.2 \%$; with 4 complete responses, 32 partial responses), DCR was 52.4\% (95\% CI, $42.4 \%$ to $62.2 \%$ ), and median PFS was 6.9 months (95\% CI, 3.1 to 8.5 months) [55]. Comparable results were described in an interim analysis of the phase 2 CARSKIN trial (NCT02883556), regarding patients with unresectable cSCC treated with pembrolizumab [56].

Moreover, there are currently ongoing studies evaluating novel therapeutic approaches in la-cSCC, such as pembrolizumab monotherapy (NCT02964559), nivolumab monotherapy (NCT03834233), pembrolizumab associated to cetuximab (NCT03082534).

Regarding la-BCC and m-BCC, there are case reports of pembrolizumab or nivolumab use, with variable results [54] and also an ongoing study evaluating nivolumab monotherapy or in combination with ipilimumab (NCT03521830). In a non-randomized open label study involving 16 patients with la-BCC, either pembrolizumab monotherapy or pembrolizumab plus vismodegib were administered. For the first group, RR at 18 weeks was $44 \%$ (4/9 patients; 95\% confidence interval $14-79 \%$ ), while for the combination therapy group, RR was $29 \%$ (2/7 patients; $95 \%$ confidence interval $4-71 \%)$ [57].

An ongoing study is investigating neoadjuvant pembrolizumab use in advanced BCC (NCT04323202).

As far as concerns advanced Merkel cell carcinoma, durable tumor regression has been recently obtained in patients treated with pembrolizumab in the KEYNOTE 017 trial (objective RR of 56\% and median PFS of 16.8 months) and United States Food and Drug Administration (FDA) approved this drug as first-line therapy for MCC [58].

In the phase I/II CheckMate 358 study, nivolumab was used as neoadjuvant option in MCC, before surgical excision [59]. Among 36 patients who underwent surgery, 17 (47.2\%) achieved a pathologic complete response and none of them showed relapse during observation [59].

The most common therapeutic scheme for pembrolizumab is 200 mg every 3 weeks, while for nivolumab is $240 \mathrm{mg}$ every 2 weeks, intravenous administration. 
Hypersensitivity to active principle or bulking agents, history of solid organ transplant, autoimmune disease, pregnancy, and lactation.

Main drug interactions

Avoid systemic steroids or immunosuppressants before administration (potential reduction of efficacy).

Nonspecific adverse effects such as fatigue, nausea, diarrhea, skin rashes, and pruritus are common and reported in 10-30\% of cases. Infusion reactions are common but mostly mild. Other notable adverse effects are liver enzymes and creatinine serum level elevation, musculoskeletal pain, arthralgia, dyspnea and cough, hypertension, xerostomia and xerophthalmia, headache, insomnia, anemia, thrombocytopenia, leukopenia, alteration of ion serum levels. Immune-related toxicity can be irreversible, severe, and rarely fatal: immune-related pneumonitis, nephritis, colitis, hepatitis, and endocrinopathies such as thyroiditis hypophysitis, adrenal insufficiency, and diabetes mellitus are reported [60,61].

Cost/cost-effectiveness

The cost is elevated.

Anti-cytotoxic T-lymphocyte-associated protein 4 immune checkpoint inhibition

\section{Ipilimumab}

Cytotoxic T-lymphocyte-associated protein 4 (CTLA4) is a T cell protein receptor that prevents $\mathrm{T}$ cell activation when bound to a costimulatory protein receptor called B7, localized on the surface of an antigen-presenting cell. Ipilimumab is an anti-CTLA4 monoclonal antibody (IgG1k), approved for melanoma and renal cell cancer (in monotherapy or in association with nivolumab).

Cutaneous squamous cell carcinoma

Data regarding ipilimumab use in NMSC are limited to case reports. A patient with metastatic melanoma and concurrent metastatic CSCC had a durable remission of both malignancies [62].

Basal cell carcinoma

Regression of an advanced BCC was similarly reported in a patient exposed to ipilimumab for a concurrent metastatic melanoma [63]. There is an ongoing study involving la-BCC or m-BCC which evaluates ipilimumab in association with nivolumab in one of the arms (NCT03521830). 
Standard dosage

$3 \mathrm{mg} / \mathrm{kg}$ intravenously every 3 weeks, for 4 doses.

Contraindications

Hypersensitivity to active principle or bulking agents, history of solid organ transplant, autoimmune disease, pregnancy, and lactation.

Main drug interactions

Avoid systemic steroids or immunosuppressants before administration (potential reduction of ipilimumab efficacy). Strict monitoring of patients using anticoagulant therapy is advisable (increased risk of gastrointestinal hemorrhage).

Main adverse effects

Skin rashes, pruritus, dermatitis, vitiligo, musculoskeletal pain, arthralgia; anorexia, diarrhea, nausea, gastrointestinal bleeding, impaired liver function; anemia, lymphopenia, dehydration, hypokalemia, headache, peripheral neuropathy, blurred vision, hypotension, dyspnea, and cough. Other immunerelated adverse effects can be irreversible, severe, and rarely fatal but are not so common: among them, pneumonitis, nephritis, hepatitis, and endocrinopathies such as thyroiditis, hypophysitis, and adrenal insufficiency are reported $[60,61]$.

The cost is elevated.

\section{Pharmacologic treatments: systemic chemotherapy}

Currently, there is no approved systemic chemotherapy agent for locally advanced and metastatic NMSC, but platinum-based protocols (cisplatin or carboplatin) have been sometimes adopted, especially for metastatic CSCC [64-66]. Therapeutic attempts with bleomycin, methotrexate, adriamycin, gemcitabine, doxorubicin, paclitaxel, ifosfamide, cyclophosphamide, etoposide, and antimetabolite pyrimidine analogs (such as 5-fluorouracil and capecitabine) are also reported $[67 \bullet \bullet, 68]$.

According to observational studies involving advanced and metastatic NMSC, overall RR is higher for polychemotherapy rather than monotherapy, but the latter is generally more tolerated and associated to less severe toxicity (essential factor for elderly people or patients with comorbidities) [67••, 69, $70]$. 


\section{Cutaneous squamous cell carcinoma}

A retrospective study involving a group of 25 patients with la-SCC and m-SCC treated with systemic therapies (chemotherapy regimens in large part) showed a RR of 44\% [69]. Unfortunately, only partial responses were reported and recurrence was the norm within months (median PFS of 5.5 months) [69]. Of note, cetuximab was included among systemic therapies in this analysis [69]. Comparable results were reported in a recent meta-analysis involving 60 cases of m-SCC treated with cisplatin: overall RR was 45\% (complete response 22\%; partial response $25 \%$ ) and median disease-free survival in responders was 14.6 months [64].

In neoadjuvant setting, cisplatin, bleomycin, and 5-fluorouracil led to good results in some dated case series, eventually allowing local control with radiation and/or surgery with better functional and cosmetic results [71-73].

\section{Basal cell carcinoma}

Systemic platinum-based chemotherapy was also used in la-BCC and m-BCC, achieving overall RR of up to $77-83 \%$, with complete response in up to $45 \%$ of treated lesions, although without long-term remissions (relapse in months) $[65,66]$.

In neoadjuvant setting, cisplatin was used prior to surgery in combination with doxorubicin, adriamycin \pm cyclophosphamide, or bleomycin, showing some efficacy, but the evidence is not so strong (small-size and outdated case series) [70].

\section{Merkel cell carcinoma}

In MCC, neoadjuvant cisplatin, etoposide, and cyclophosphamide regimen led to local control in two patients, allowing curative surgery associated with adjuvant radiation therapy [68].

\section{Cisplatin}

Standard dosage

Platinum-based protocols represent the most common approach, if chemotherapy is chosen.

Dosage of intravenous cisplatin varied from 20 to $100 \mathrm{mg} / \mathrm{m}^{2}$ in different studies (depending on mono or polychemotherapy) [69, 70].

Hypersensitivity to active principle or bulking agents, pregnancy and lactation, renal dysfunction, myelosuppression, auditory alteration, and platinum-related neuropathy. 
Avoid concomitant nephrotoxic agents (such as aminoglycosides, amphotericin B, contrast medium) or ototoxic drugs (for example, aminoglycosides and loop diuretics). Avoid live attenuated vaccines (risk of fatal systemic disease). Strict patient monitoring is advisable in case of concomitant oral anticoagulant use. Contemporary use of antihistamines can mask ototoxicity symptoms. Exposition to anticonvulsant drug may decrease [58-61, 63, 64].

Main adverse effects

Hematologic (leukopenia, thrombocytopenia, anemia) and gastrointestinal adverse effects (anorexia, nausea, vomit, diarrhea), auditory disturbances, renal alterations (renal failure, nephrotoxicity, hyperuricemia), arrythmias $[64-66,67 \bullet \bullet, 69,70]$.

This treatment is less expensive than targeted therapy or immunotherapy; multiple infusions are required.

\section{Interventional procedures}

\section{Intralesional chemotherapy}

Intralesional administration of chemotherapy agents such as 5-fluorouracil, bleomycin, and interferon has been used in BCCs, SCCs, and keratoacanthomas [74]. 5-Fluorouracil is an antimetabolite and structural analog of uracil and acts by disrupting DNA and RNA [75], bleomycin is cytotoxic and causes DNA damage, while interferon acts as an antiproliferative and immune-stimulating drug [74]. Major contraindications for intralesional chemotherapy are pregnancy and lactation, while caution is advisable in patients with renal and hepatic disease [74]. Only local discomfort is generally reported (pain, erythema, crusting, ulceration, necrosis), but systemic side effects are possible (such as cytopenia, gastrointestinal upset, hepato- and nephrotoxicity, teratogenesis) [74].

\section{Intralesional methotrexate}

Methotrexate is a folic acid analog, which inhibits DNA synthesis in actively dividing cells, irreversibly binding to dihydrofolate reductase and therefore blocking the formation of tetrahydrofolate [76]. This mechanism prevents the downstream synthesis of the nucleotide thymidine [76].

Intralesional methotrexate (MTX) showed efficacy for primary cSCC, in particular for well-differentiated subtype and keratoacanthomas [76-79]. Its use as neoadjuvant treatment was investigated in a retrospective study on 86 cSCCs [77]. The group undergoing neoadjuvant intralesional MTX administration before surgery (half of the lesions, $n=43$ ) showed an average reduction in 
cSCC size of $0.52 \mathrm{~cm}^{2}$, whereas the group scheduled for excision was characterized by $0.49 \mathrm{~cm}^{2}$ area increase [77]. The data of this study also suggested a reduced rate of complex surgical reconstructions (local flaps or grafts) in treated tumors, especially in lesions $\geq 2 \mathrm{~cm}$ in diameter [77].

Standard procedure

No standard procedure is established. For example, in the aforementioned study, MTX was administered into the base of the tumor until it acquired a yellowish color, with a mean MTX quantity of $0.74 \mathrm{~mL}(0.1-1.3 \mathrm{~mL})$, corresponding to $2.5-32.5 \mathrm{mg}$ [77]. One or more injections (repeated weekly) are usually performed [76-79]. A dose of $10 \mathrm{mg}$ of folic acid is sometimes administered $24 \mathrm{~h}$ after the procedure [79].

\section{Contraindications}

Hypersensitivity to methotrexate, pregnancy, or lactation. Hematological abnormalities, liver or kidney disease may be considered relative contraindications [77].

Pain, erythema, crusting, ulceration, and necrosis are quite common [78]. Topical anesthesia or concomitant use of lidocaine and epinephrine may help reduce the pain; moreover, epinephrine-induced vasoconstriction decreases diffusion of the chemotherapy agent [78]. Pancytopenia occurring after a $25 \mathrm{mg}$ intralesional MTX injection has been previously reported in patients with hemodialysis-dependent renal failure [76]. Although these adverse events are rare, performing a baseline and post-injection complete blood cell count is advisable to detect for potential subclinical MTXinduced cytopenia [76].

This technique is relatively inexpensive.

As far as concerns electrochemotherapy (ECT), this procedure uses electrical pulses to increase absorption of a chemotherapy agent (usually bleomycin, less frequently cisplatin) administered intravenously or intratumorally [80].

ECT is used for primary, locally advanced and metastatic NMSC and is considered a safe and well-tolerated treatment. In a multicenter prospective study involving a total of 105 patients affected by primary or recurrent skin cancer of the head and neck area, ECT reached an objective RR of $97 \%$ for BCC and $79 \%$ for cSCC after 2 months [81]. Of note, the best response was obtained in tumors smaller than $3 \mathrm{~cm}$ in diameter [81]. 
procedure is performed under general or local anesthesia: the first option is preferred if numerous or large nodules are treated. Electrical pulses (eight pulses of $100 \mathrm{~ms}$ duration, amplitude of $1000-1300 \mathrm{~V} / \mathrm{cm}$ ) are delivered with an electroporator immediately after the intratumoral injection or $8 \mathrm{~min}$ after the intravenous injection of bleomycin. Treated lesions form an eschar as necrosis occurs about 10-14 days after the procedure [80-82].

\section{Contraindications}

Pregnancy and lactation, history of hypersensitivity to bleomycin or cisplatin. In presence of a history of pulmonary disease or renal impairment, a dose reduction may be required [80].

Pain at the electroporation site is quite common but can be normally managed with paracetamol or other simple analgesic drugs. Acute toxicity is minimal; chemotherapy adverse effects are rare (bleomycin pulmonary fibrosis is reported, but it is exceptional) [80].

An equipped operating room and specialized professionals are required, increasing the costs. General anesthesia is sometimes necessary.

\section{Photodynamic therapy}

Photodynamic therapy (PDT) uses 5-aminolevulinic acid (5-ALA) or methylaminolevulinic acid (MAL). They both are precursors of heme in its biosynthetic pathway and form intermediate porphyrins such as the photoactive compound protoporphyrin IX. When excited by light of an adequate wavelength, protoporphyrin IX forms reactive oxygen species, leading to tumoral cell death by necrosis and apoptosis (the mechanisms are direct cytotoxicity, damage to the tumor vasculature, and activation of the immune response) [83].

Actinic keratoses, superficial BCC, and Bowen's disease/squamous cell carcinoma in situ are approved indications for PDT [84]. This technique can be also used for nodular BCCs, but response is inferior and recurrence rate is high, especially for lesions thicker than $2-3 \mathrm{~mm}$; in addition, heavily pigmented lesions such as pigmented BCCs show less response [84, 85].

PDT was used as neoadjuvant treatment in reducing lesion size for facial tumors (BCCs and SCCs) localized in functionally and aesthetically sensitive areas, showing improvement of the lesions and area reduction for most lesions $[85,86]$. applied. An incubation time is necessary (usually 3-6 h) and treated areas are subsequently exposed to light, generally using lamps $[83,84]$. 
Known history of porphyria or allergic reactions to active ingredients or bulking agents of the applied sensitizers [83].

Stinging pain and burning sensation during light exposure is quite common. Subsequent localized erythema and edema in the treated area are usually seen. Over the days following the treatment, erosions and crusting precede reepithelization [83].

In addition to the photosensitizer cost, the procedure itself requires special equipment and qualified personnel. More than one session is usually needed (at least two or three treatments) $[85,86]$.

\section{Emerging therapies}

Considering the high mutational burden and antigenicity of NMSC, immunotherapy appears to be one of the most promising fields. Anti-PD-L1 antibodies such as avelumab, atezolizumab, and cosibelimab act by interfering with the PD-1 pathway, similarly to pembrolizumab and nivolumab.

Of note, avelumab has been approved by FDA for metastatic MCC and has also been used for this malignancy in neoadjuvant setting: of ten eligible patients that underwent surgery, four $(40 \%)$ reached a pathological complete response $[87 \bullet]$.

Ongoing studies for advanced cSCC are evaluating avelumab with or without cetuximab (NCT03944941), avelumab with radiotherapy (NCT03737721), atezolizumab together with cobimetinib, MEK inhibitor (NCT03108131), cosibelimab (NCT03212404), and SL-279252, a PD-1-FC-OX40L checkpoint fusion protein that acts as an immune system agonist (NCT03894618).

Moreover, intralesional administration of talimogene laherparepvec (TVEC), a genetically modified herpes simplex virus-1, is currently being evaluated for advanced NMSC (NCT03458117).

\section{Conclusion and summary}

Given the actual evidence, targeted therapy with sonic hedgehog inhibitors for BCC and immunotherapy for all NMSCs (in particular, CSCC and MCC) are the most promising strategies in a neoadjuvant setting, being much more selective than traditional chemotherapy. On the other hand, targeted therapy for CSCC appears to be at its dawn, given the modest results gained by EGFR inhibitors. A more detailed comprehension of squamous cell carcinogenesis is needed to develop new strategies. Unfortunately, all these aforementioned novel treatments are actually quite expensive and immunotherapy can lead to severe and 
irreversible adverse effects. In addition, not all treated lesions show good response and recurrence rates are elevated; therefore, further research is required to overcome these difficulties. Finally, we do not have to forget that also other less expensive approaches exist, such as intralesional chemotherapy, PDT, and electrochemotherapy. Neoadjuvant approach for NMSC is a promising field and will be probably approved in the near future.

\section{Funding}

Open access funding provided by Università degli Studi di Trieste within the CRUI-CARE Agreement.

\section{Declarations}

\section{Conflict of Interest}

Enrico Zelin declares that he has no conflict of interest. Iris Zalaudek declares that she has no conflict of interest. Marina Agozzino declares that she has no conflict of interest. Caterina Dianzani declares that she has no conflict of interest. Arianna Dri declares that she has no conflict of interest. Nicola Di Meo declares that he has no conflict of interest. Roberta Giuffrida declares that she has no conflict of interest. Giovanni Francesco Marangi declares that he has no conflict of interest. Nicoleta Neagu declares that she has no conflict of interest. Paolo Persichetti declares that he has no conflict of interest. Ludovica Toffoli declares that she has no conflict of interest. Claudio Conforti declares that he has no conflict of interest.

\section{Human and Animal Rights and Informed Consent}

This article does not contain any studies with human or animal subjects performed by any of the authors.

\section{Open Access}

This article is licensed under a Creative Commons Attribution 4.0 International License, which permits use, sharing, adaptation, distribution and reproduction in any medium or format, as long as you give appropriate credit to the original author(s) and the source, provide a link to the Creative Commons licence, and indicate if changes were made. The images or other third party material in this article are included in the article's Creative Commons licence, unless indicated otherwise in a credit line to the material. If material is not included in the article's Creative Commons licence and your intended use is not permitted by statutory regulation or exceeds the permitted use, you will need to obtain permission directly from the copyright holder. To view a copy of this licence, visit http://creativecommons.org/licenses/by/4.0/.

\section{References and Recommended Reading}

Papers of particular interest, published recently, have been highlighted as:

- Of importance

-. Of major importance

1. Rogers HW, Weinstock MA, Feldman SR, Coldiron BM. Incidence estimate of nonmelanoma skin cancer (keratinocyte carcinomas) in the US population, 2012.

JAMA Dermatol. 2015;151:1081. https://doi.org/10. 1001/jamadermatol.2015.1187. 
2. Nehal KS, Bichakjian CK. Update on keratinocyte carcinomas. Longo DL, editor. N Engl J Med. 2018;379:363-74. https://doi.org/10.1056/ NEJMra1708701.

3. Di Meo N, Conforti C, Vezzoni R, Retrosi C, Longone $\mathrm{M}$, Fadel M, et al. Basal cell carcinomas are not only UV-related. G Ital Dermatol Venereol. 2020. https:// doi.org/10.23736/S0392-0488.20.06357-9 Epub ahead of print.

4. Conforti C, Giuffrida R, Vezzoni R, Resende FSS, Meo N, Zalaudek I. Dermoscopy and the experienced clinicians. Int J Dermatol. 2020;59:16-22. https://doi.org/ 10.1111/ijd.14512.

5. Conforti C, Giuffrida R, Retrosi C, di Meo N, Zalaudek I. Two controversies confronting dermoscopy or dermatoscopy: nomenclature and results. Clin Dermatol. 2019;37:597-9. https://doi.org/10.1016/j. clindermatol.2019.07.001.

6. Giuffrida R, Conforti C, Di Meo N, Deinlein T, Guida S, Zalaudek I. Use of noninvasive imaging in the management of skin cancer. Curr Opin Oncol. 2020;32:98105. https://doi.org/10.1097/CCO. 0000000000000611.

7. Veness MJ, Delishaj D, Barnes EA, Bezugly A, Rembielak A. Current role of radiotherapy in non-melanoma skin cancer. Clin Oncol Elsevier Ltd. 2019;31:749-58. https://doi.org/10.1016/j.clon.2019.08.004.

8. $\quad$ Garbutcheon-Singh KB, Veness MJ. The role of radiotherapy in the management of non-melanoma skin cancer. Australas J Dermatol. 2019;60:265-72. https:// doi.org/10.1111/ajd.13025

In this article, the role of radiotherapy in non-melanoma skin cancer is reviewed.

9. Grossi Marconi D, da Costa RB, Rauber E, de Cassia SP, Fernandes JM, Mehta N, et al. Head and neck non-melanoma skin cancer treated by superficial X-ray therapy: an analysis of 1021 cases. Li JJ, editor. PLoS One. 2016;11:e0156544. https://doi.org/10.1371/journal.pone.0156544.

10. Niebel D, Sirokay J, Hoffmann F, Fröhlich A, Bieber T, Landsberg J. Clinical management of locally advanced basal-cell carcinomas and future therapeutic directions. Dermatol Ther (Heidelb). 2020;10:835-46. https:// doi.org/10.1007/s13555-020-00382-y.

11. Gellrich FF, Beissert S, Eigentler T, Stock E, Gutzmer R, Meier F. Medical treatment of advanced cutaneous squamous-cell carcinoma. 2020:38-43. https://doi. org/10.1111/jdv.16024.

12. Schwartz LH, Litière $\mathrm{S}$, de Vries E, Ford R, Gwyther S, Mandrekar S, et al. RECIST 1.1-update and clarification: from the RECIST committee. Eur J Cancer. 2016;62:132-7. https://doi.org/10.1016/j.ejca.2016. 03.081 .

13. Eisenhauer EA, Therasse P, Bogaerts J, Schwartz LH, Sargent D, Ford R, et al. New response evaluation criteria in solid tumours: revised RECIST guideline (version 1.1). Eur J Cancer Elsevier Ltd. 2009;45:22847. https://doi.org/10.1016/j.ejca.2008.10.026.
14.• Migden MR. Targeted therapies in the treatment of advanced basal cell carcinoma. Clin Res Trials. 2018;4:1-6. https://doi.org/10.15761/CRT.1000231

In this article, targeted therapies for advanced BCC are reviewed.

15. Maubec E, Petrow P, Scheer-Senyarich I, Duvillard P, Lacroix L, Gelly J, et al. Phase II study of cetuximab as first-line single-drug therapy in patients with unresectable squamous cell carcinoma of the skin. J Clin Oncol. 2011;29:3419-26. https://doi.org/10. 1200/JCO.2010.34.1735.

16. Foote MC, McGrath M, Guminski A, Hughes BGM, Meakin J, Thomson D, et al. Phase II study of single-agent panitumumab in patients with incurable cutaneous squamous cell carcinoma. Ann Oncol. 2014;25:204752. https://doi.org/10.1093/annonc/mdu368.

17. Gold KA, Kies MS, William WN, Johnson FM, Lee JJ, Glisson BS. Erlotinib in the treatment of recurrent or metastatic cutaneous squamous cell carcinoma: a singlearm phase 2 clinical trial. Cancer. 2018;124:2169-73. https://doi.org/10.1002/cncr.31346.

18. William WN, Feng L, Ferrarotto R, Ginsberg L, Kies M, Lippman S, et al. Gefitinib for patients with incurable cutaneous squamous cell carcinoma: a single-arm phase II clinical trial. J Am Acad Dermatol. Elsevier Inc. 2017;77:1110-1113.e2. https://doi.org/10.1016/j. jaad.2017.07.048.

19. Jenni D, Karpova M, Mühleisen B, Mangana J, Dreier J, Hafner J, et al. A prospective clinical trial to assess lapatinib effects on cutaneous squamous cell carcinoma and actinic keratosis. ESMO Open.

2016;1:e000003. https://doi.org/10.1136/esmoopen2015-000003.

20. Cavalieri S, Perrone F, Miceli R, Ascierto PA, Locati LD, Bergamini C, et al. Efficacy and safety of single-agent pan-human epidermal growth factor receptor (HER) inhibitor dacomitinib in locally advanced unresectable or metastatic skin squamous cell cancer. Eur J Cancer.

Elsevier Ltd. 2018;97:7-15. https://doi.org/10.1016/j.ejca.

2018.04.004.

21. Picard A, Pedeutour F, Peyrade F, Saudes L, DurantonTanneur V, Chamorey E, et al. Association of oncogenic mutations in patients with advanced cutaneous squamous cell carcinomas treated with cetuximab. JAMA Dermatol. 2017;153:291. https://doi.org/10.1001/ jamadermatol.2017.0270.

22. Sekulic A, Migden MR, Oro AE, Dirix L, Lewis KD, Hainsworth JD, et al. Efficacy and safety of vismodegib in advanced basal-cell carcinoma. N Engl J Med. 2012;366:2171-9. https://doi.org/10.1056/ nejmoa1113713.

23. Sekulic A, Migden MR, Lewis K, Hainsworth JD, Solomon JA, Yoo S, et al. Pivotal ERIVANCE basal cell carcinoma (BCC) study: 12-month update of efficacy and safety of vismodegib in advanced BCC. J Am Acad Dermatol. Elsevier Inc. 2015;72:1021-1026.e8. https://doi.org/10.1016/j.jaad.2015.03.021.

24. Sekulic A, Migden MR, Basset-Seguin N, Garbe C, Gesierich A, Lao CD, et al. Long-term safety and 
efficacy of vismodegib in patients with advanced basal cell carcinoma: final update of the pivotal ERIVANCE BCC study. BMC Cancer BMC Cancer. 2017;17:332. https://doi.org/10.1186/s12885-017-3286-5.

25. Basset-Seguin N, Hauschild A, Grob JJ, Kunstfeld R, Dréno B, Mortier L, et al. Vismodegib in patients with advanced basal cell carcinoma (STEVIE): a pre-planned interim analysis of an international, open-label trial Lancet Oncol. 2015;16:729-36. https://doi.org/10. 1016/S1470-2045(15)70198-1.

26. Basset-Séguin N, Hauschild A, Kunstfeld R, Grob J, Dréno B, Mortier L, et al. Vismodegib in patients with advanced basal cell carcinoma: primary analysis of STEVIE, an international, open-label trial. Eur J Cancer. 2017;86:334-48. https://doi.org/10.1016/j.ejca.2017. 08.022 .

27. Pollom EL, Bui TT, Chang ALS, Colevas AD, Hara WY. Concurrent vismodegib and radiotherapy for recurrent, advanced basal cell carcinoma. JAMA Dermatol. 2015;151:998. https://doi.org/10.1001/jamadermatol. 2015.0326.

28. Kwon GP, Ally MS, Bailey-Healy I, Oro AE, Kim J, Chang AL, et al. Update to an open-label clinical trial of vismodegib as neoadjuvant before surgery for high-risk basal cell carcinoma (BCC). J Am Acad Dermatol. 2016;75:213-5. https://doi.org/10.1016/j.jaad.2016. 02.1235 .

29. Malhi V, Colburn D, Williams SI, Hop CECA, Dresser MJ, Chandra P, et al. A clinical drug-drug interaction study to evaluate the effect of a proton-pump inhibitor, a combined P-glycoprotein/cytochrome 450 enzyme (CYP)3A4 inhibitor, and a CYP2C9 inhibitor on the pharmacokinetics of vismodegib. Cancer Chemother Pharmacol. Springer. Berlin Heidelberg. 2016;78:41-9. https://doi.org/10.1007/s00280-016-3020-z.

30. Meiss F, Andrlovà H, Zeiser R. Vismodegib. In: Martens UM, editor. Small Mol Oncol. Cham: Springer International Publishing; 2018. p. 126-34. https://doi.org/ 10.1007/978-3-319-91442-8.

31. Lear JT, Migden MR, Lewis KD, Chang ALS, Guminski A, Gutzmer R, et al. Long-term efficacy and safety of sonidegib in patients with locally advanced and metastatic basal cell carcinoma: 30-month analysis of the randomized phase 2 BOLT study. J Eur Acad Dermatol Venereol. 2018;32:372-81. https://doi.org/10.1111/ jdv.14542.

32. Burness CB. Sonidegib: first global approval. Drugs. Springer International Publishing. 2015;75:1559-66. https://doi.org/10.1007/s40265-015-0458-y.

33. Conforti C, Giuffrida R, MEO NDI, Zalaudek I. Management of locally advanced basal cell carcinoma treated with Sonidegib: the experience of an italian reference hospital. Dermatol Ther. 2020:dth.14511. https://doi.org/10.1111/dth.14511.

34.• Chen L, Aria AB, Silapunt S, Migden MR. Emerging nonsurgical therapies for locally advanced and metastatic nonmelanoma skin cancer. Dermatol Surg. 2019;45:1-16. https://doi.org/10.1097/DSS. 0000000000001601
In this article, all main systemic treatments for advanced and metastatic NMSC are reviewed.

35. Joseph K, Alkaabi K, Warkentin H, Ghosh S, Jha N, Smylie $\mathrm{M}$, et al. Cetuximab-radiotherapy combination in the management of locally advanced cutaneous squamous cell carcinoma. J Med Imaging Radiat Oncol. 2019;63:257-63. https://doi.org/10.1111/ 1754-9485.12842.

36. Reigneau M, Robert C, Routier E, Mamelle G, MoyaPlana A, Tomasic G, et al. Efficacy of neoadjuvant cetuximab alone or with platinum salt for the treatment of unresectable advanced nonmetastatic cutaneous squamous cell carcinomas. Br J Dermatol. 2015;173:527-34. https://doi.org/10.1111/bjd. 13741.

37. Preneau S, Rio E, Brocard A, Peuvrel L, Nguyen J, Quéreux G, et al. Efficacy of cetuximab in the treatment of squamous cell carcinoma. J Dermatol Treat. 2014;25:424-7. https://doi.org/10.3109/09546634. 2012.751481.

38. Samstein RM, Ho AL, Lee NY, Barker CA. Locally advanced and unresectable cutaneous squamous cell carcinoma: outcomes of concurrent cetuximab and radiotherapy. J Skin Cancer Hindawi Publishing Corporation. 2014;2014:1-7. https://doi.org/10.1155/2014/ 284582.

39. Petrelli F, Ardito R, Ghidini A, Zaniboni A, Ghidini M, Barni S, et al. Different toxicity of cetuximab and panitumumab in metastatic colorectal cancer treatment: a systematic review and meta-analysis. Oncology. 2018;94:191-9. https://doi.org/10.1093/annonc/ mdy2584.

40. Wollina U. Cetuximab in non-melanoma skin cancer. Expert Opin Biol Ther. 2012;12:949-56. https://doi. org/10.1517/14712598.2012.681374.

41. Hourbeigt K, Ehret M, Visseaux L, Durlach A, Petit A, Sanchez J, et al. Efficacy and safety of panitumumab alone or in association with radiotherapy in unresectable cutaneous squamous cell carcinoma. J Eur Acad Dermatol Venereol. 2020:jdv.16465. https://doi. org/10.1111/jdv.16465.

42. Hartmann J, Haap M, Kopp H-G, Lipp H-P. Tyrosine kinase inhibitors - a review on pharmacology, metabolism and side effects. Curr Drug Metab. 2009;10:47081. https://doi.org/10.2174/138920009788897975.

43. Kucharczuk R. DNP, CRNP C, Ganetsky, PharmD, BCOP A, Michael Vozniak, PharmD, BCOP J. Drugdrug interactions, safety, and pharmacokinetics of EGFR tyrosine kinase inhibitors for the treatment of non-small cell lung cancer. J Adv Pract Oncol. 2018;9:189-200. https://doi.org/10.6004/jadpro. 2018.9.2.5.

44.• Barrios DM, Do MH, Phillips GS, Postow MA, Akaike T, Nghiem P, et al. Immune checkpoint inhibitors to treat cutaneous malignancies. J Am Acad Dermatol American Academy of Dermatology, Inc. 2020;83:1239-53. https://doi.org/10.1016/j.jaad.2020.03.131

This article is a good review regarding immunotherapies used in NMSC. 
45. McGranahan N, Furness AJS, Rosenthal R, Ramskov S, Lyngaa R, Saini SK, et al. Clonal neoantigens elicit T cell immunoreactivity and sensitivity to immune checkpoint blockade. Science (80- ). 2016;351:1463-9. https://doi.org/10.1126/science.aaf1490.

46. Migden MR, Rischin D, Schmults CD, Guminski A, Hauschild A, Lewis KD, et al. PD-1 blockade with cemiplimab in advanced cutaneous squamous-cell carcinoma. N Engl J Med. 2018;379:341-51. https:// doi.org/10.1056/NEJMoa1805131.

47. Falchook GS, Leidner R, Stankevich E, Piening B, Bifulco C, Lowy I, et al. Responses of metastatic basal cell and cutaneous squamous cell carcinomas to antiPD1 monoclonal antibody REGN2810. J Immunother Cancer. Journal for ImmunoTherapy of Cancer. 2016;4:70. https://doi.org/10.1186/s40425-016-01763.

48. Markham A, Duggan S. Cemiplimab: first global approval. Drugs. Springer International Publishing. 2018;78:1841-6. https://doi.org/10.1007/s40265018-1012-5.

49. Stevenson ML, Wang CQF, Abikhair M, Roudiani N, Felsen D, Krueger JG, et al. Expression of programmed cell death ligand in cutaneous squamous cell carcinoma and treatment of locally advanced disease with pembrolizumab. JAMA Dermatol. 2017;153:299. https://doi.org/10.1001/jamadermatol.2016.5118.

50. Borradori L, Sutton B, Shayesteh P, Daniels GA. Rescue therapy with anti-programmed cell death protein 1 inhibitors of advanced cutaneous squamous cell carcinoma and basosquamous carcinoma: preliminary experience in five cases. Br J Dermatol. 2016;175:1382-6. https://doi.org/10.1111/bjd.14642.

51. Tran DC, Colevas AD, Chang ALS. Follow-up on programmed cell death 1 inhibitor for cutaneous squamous cell carcinoma. JAMA Dermatol. 2017;153:92. https://doi.org/10.1001/jamadermatol.2016.3884.

52. Blum V, Hofer S, Pardo E, Zeidler K, Diebold J, Strobel $K$, et al. Nivolumab for recurrent cutaneous squamous cell carcinoma: three cases. 2018;28:78-81. https://doi. org/10.1684/ejd.2017.3209.

53. Chen A, Ali N, Boasberg P, Ho A. Clinical remission of cutaneous squamous cell carcinoma of the auricle with cetuximab and nivolumab. J Clin Med. 2018;7:10. https://doi.org/10.3390/jcm7010010.

54. Choi FD, Kraus CN, Elsensohn AN, Carley SK, Lehmer LM, Nguyen RT, et al. Programmed cell death 1 protein and programmed death-ligand 1 inhibitors in the treatment of nonmelanoma skin cancer: a systematic review [Internet]. J Am Acad Dermatol. American Academy of Dermatology, Inc. 2020. https://doi.org/ 10.1016/j.jaad.2019.05.077.

55. Grob J-J, Gonzalez R, Basset-Seguin N, Vornicova O, Schachter J, Joshi A, et al. Pembrolizumab monotherapy for recurrent or metastatic cutaneous squamous cell carcinoma: a single-arm phase II trial (KEYNOTE629). J Clin Oncol. 2020;38:2916-25. https://doi.org/ 10.1200/JCO.19.03054.
56. Maubec E, Boubaya M, Petrow P, Basset-Seguin N, Grob J-J, Dreno B, et al. Pembrolizumab as first line therapy in patients with unresectable squamous cell carcinoma of the skin: interim results of the phase 2 CARSKIN trial. J Clin Oncol. 2018;36:9534. https:// doi.org/10.1200/JCO.2018.36.15_suppl.9534.

57. Chang ALS, Tran DC, Cannon JGD, Li S, Jeng M, Patel $\mathrm{R}$, et al. Pembrolizumab for advanced basal cell carcinoma: an investigator-initiated, proof-of-concept study. J Am Acad Dermatol Elsevier. 2019;80:564-6. https://doi.org/10.1016/j.jaad.2018.08.017.

58. Nghiem P, Bhatia S, Lipson EJ, Sharfman WH, Kudchadkar RR, Brohl AS, et al. Durable tumor regression and overall survival in patients with advanced Merkel cell carcinoma receiving pembrolizumab as first-line therapy. J Clin Oncol. 2019;37:693-702. https://doi.org/10.1200/JCO.18.01896.

59. Topalian SL, Bhatia S, Amin A, Kudchadkar RR, Sharfman WH, Lebbé C, et al. Neoadjuvant nivolumab for patients with resectable merkel cell carcinoma in the CheckMate 358 Trial. J Clin Oncol. 2020;38:2476-87. https://doi.org/10.1200/ JCO.20.00201.

60. Spiers L, Coupe N, Payne M. Toxicities associated with checkpoint inhibitors-an overview. Rheumatology. 2019;58:vii7-16. https://doi.org/10.1093/ rheumatology/kez418.

61. Marin-Acevedo JA, Chirila RM, Dronca RS. Immune checkpoint inhibitor toxicities. Mayo Clin Proc. Mayo Foundation for Medical Education and Research. 2019;94:1321-9. https://doi.org/10.1016/j.mayocp. 2019.03.012.

62. Day F, Kumar M, Fenton L, Gedye C. Durable response of metastatic squamous cell carcinoma of the skin to ipilimumab immunotherapy. J Immunother. 2017;40:36-8. https://doi.org/10.1097/CJI. 0000000000000146.

63. Mohan SV, Kuo KY, Chang ALS. Incidental regression of an advanced basal cell carcinoma after ipilimumab exposure for metastatic melanoma. JAAD Case Rep. Elsevier Inc. 2016;2:13-5. https://doi.org/10.1016/j. jdcr.2015.11.007.

64. Trodello C, Pepper J, Wong M, Wysong A. Cisplatin and cetuximab treatment for metastatic cutaneous squamous cell carcinoma. Dermatol Surg. 2017;43:40-9. https://doi.org/10.1097/DSS. 0000000000000799.

65. Moeholt K, Aagaard H, Pfeiffer P, Hansen O. Platinumbased cytotoxic therapy in basal cell carcinoma a review of the literature. Acta Oncol (Madr). 1996;35:677-82. https://doi.org/10.3109/ 02841869609083998.

66. Pfeiffer P, Hansen O, Rose C. Systemic cytotoxic therapy of basal cell carcinoma. Eur J Cancer Clin Oncol. 1990;26:73-7. https://doi.org/10.1016/02775379(90)90262-R.

67.• Conforti C, Corneli P, Harwood C, Zalaudek I. Evolving role of systemic therapies in non-melanoma skin cancer. Clin Oncol Elsevier Ltd. 2019;31:759-68. 
https://doi.org/10.1016/j.clon.2019.08.011

In this article, all main systemic treatments for advanced and metastatic NMSC are reviewed.

68. Jouary T, Lalanne N, Siberchicot F, Ricard A-S, Versapuech J, Lepreux S, et al. Neoadjuvant polychemotherapy in locally advanced Merkel cell carcinoma. Nat Rev Clin Oncol. Nat Publ Group. 2009;6:544-8. https://doi.org/10.1038/nrclinonc. 2009.109.

69. Jarkowski A, Hare R, Loud P, Skitzki JJ, Kane JM, May $\mathrm{KS}$, et al. Systemic therapy in advanced cutaneous squamous cell carcinoma (CSCC). Am J Clin Oncol. 2016;39:545-8. https://doi.org/10.1097/COC. 0000000000000088

70. Peris K, Tambone S, Kostaki D, Varrassi E, Fargnoli MC. Treatments of advanced basal cell carcinoma: a review of the literature. G Ital Dermatol Venereol. 2016;151:77-86.

71. Cartei G, Cartei F, Interlandi G, Meneghini G, Jop A, Zingone $\mathrm{G}$, et al. Oral 5-fluorouracil in squamous cell carcinoma of the skin in the aged. Am J Clin Oncol Cancer Clin Trials. 2000;23:181-4. https://doi.org/10. 1097/00000421-200004000-00015.

72. Denic S. Preoperative treatment of advanced skin carcinoma with cisplatin and bleomycin. Am J Clin Oncol. 1999;22:32-4. https://doi.org/10.1097/ 00000421-199902000-00008.

73. DeConti RC. Chemotherapy of squamous cell carcinoma of the skin. Semin Oncol. Elsevier Inc. 2012;39:145-9. https://doi.org/10.1053/j. seminoncol.2012.01.002.

74. Kirby JS, Miller CJ. Intralesional chemotherapy for nonmelanoma skin cancer: a practical review. J Am Acad Dermatol. Elsevier Inc. 2010;63:689-702. https://doi.org/10.1016/j.jaad.2009.09.048.

75. Metterle L, Nelson C, Patel N. Intralesional 5fluorouracil (FU) as a treatment for nonmelanoma skin cancer (NMSC): a review. J Am Acad Dermatol. Elsevier Inc. 2016;74:552-7. https://doi.org/10.1016/j. jaad.2015.09.040

76. Annest NM, VanBeek MJ, Arpey CJ, Whitaker DC. Intralesional methotrexate treatment for keratoacanthoma tumors: a retrospective study and review of the literature. J Am Acad Dermatol. 2007;56:989-93. https://doi.org/10.1016/j.jaad.2006. 12.017 .

77. Salido-Vallejo R, Cuevas-Asencio I, Garnacho-Sucedo G, González-Menchen A, Alcántara-Reifs C, De la Corte-Sánchez S, et al. Neoadjuvant intralesional methotrexate in cutaneous squamous cell carcinoma: a comparative cohort study. J Eur Acad Dermatol Venereol. 2016;30:1120-4. https://doi.org/10.1111/ jdv.13266.

78. Hoegler KM, Schleichert RA. Is the first-line treatment of keratoacanthomas surgical excision or injection of intralesional chemotherapy? J Am Acad Dermatol. American Academy of Dermatology, Inc. 2020;83:1542-3. https://doi.org/10.1016/j.jaad.2020. 01.090 .
79. Scalvenzi M, Patrì A, Costa C, Megna M, Napolitano M, Fabbrocini $\mathrm{G}$, et al. Intralesional methotrexate for the treatment of keratoacanthoma: the Neapolitan experience. Dermatol Ther (Heidelb). 2019;9:369-72. https://doi.org/10.1007/s13555-019-0286-1.

80. O'Donoghue N, Mowatt D, Sykes AJ. Electrochemotherapy and ablative therapies in nonmelanoma skin cancer. Clin Oncol (R Coll Radiol) Elsevier Ltd. 2019;31:e1-9. https://doi.org/10.1016/j. clon.2019.08.010.

81. Bertino G, Sersa G, De Terlizzi F, Occhini A, Plaschke CC, Groselj A, et al. European Research on Electrochemotherapy in Head and Neck Cancer (EURECA) project: results of the treatment of skin cancer. Eur J Cancer. 2016;63:41-52. https://doi.org/ 10.1016/j.ejca.2016.05.001.

82. Mir LM, Gehl J, Sersa G, Collins CG, Garbay J-R, Billard $\mathrm{V}$, et al. Standard operating procedures of the electrochemotherapy: instructions for the use of bleomycin or cisplatin administered either systemically or locally and electric pulses delivered by the CliniporatorTM by means of invasive or non-invasive electrodes. Eur J Cancer Suppl. 2006;4:14-25. https:// doi.org/10.1016/j.ejcsup.2006.08.003.

83. Klein A, Babilas P, Karrer S, Landthaler M, Szeimies RM. Photodynamic therapy in dermatology - an update 2008. JDDG. 2008;6:839-45. https://doi.org/10.1111/ j.1610-0387.2008.06697.x.

84. Queirós C, Garrido PM, Maia Silva J, Filipe P. Photodynamic therapy in dermatology: beyond current indications. Dermatol Ther. 2020:1-7. https://doi.org/ 10.1111/dth.13997.

85. Jeremic G, Moore CC, Brandt MG, Doyle PC. Neoadjuvant use of photodynamic therapy in basal cell and squamous cell carcinomas of the face. ISRN Dermatol. 2011;2011:1-5. https://doi.org/10.5402/2011/ 809409.

86. Jeremic G, Brandt MG, Jordan K, Doyle PC, Yu E, Moore CC. Using photodynamic therapy as a neoadjuvant treatment in the surgical excision of nonmelanotic skin cancers: prospective study. J Otolaryngol Head Neck Surg. 2011;40(Suppl 1):S829.

87. Brohl AS, Sondak VK. Neoadjuvant checkpoint inhibitor therapy for Merkel cell carcinoma. J Clin Oncol. 2020;38:2471-5. https://doi.org/10.1200/JCO.20. 00752 .

In this article, neoadjuvant immunotherapy for MCC is reviewed.

\section{Publisher's note}

Springer Nature remains neutral with regard to jurisdictional claims in published maps and institutional affiliations. 